\title{
The description of condyle position in disc displacement with reduction using Cone Beam Computed Tomography 3D radiographic analysis
}

\author{
Liana Rahmayani*, Erna Kurnikasari**, Rasmi Rikmasari** \\ *Dentistry Study Programme Faculty of Medicine Universitas Syiah Kuala Darussalam \\ **Department of Prosthodontic Faculty of Dentistry Universitas Padjadjaran
}

ABSTRACT

One of temporomandibular joint disorders that mostly occurs is disc displacement with reduction. Disc displacement that causes the displacement of condyle position can be evaluated by using radiograph. The Cone Beam Computed Tomography (CBCT-3D) is a radiograph equipment which is able to capture the condyle position from many directions. This research was aimed to see the condyle position in patients with disc displacement with reduction symptoms. This research was conducted to 11 patients with symptoms of disc displacement with reduction and 3 patients without symptoms of disc displacement with reduction as the counterpart. What was conducted to the sample was the radiographic imaging using CBCT-3D radiography, followed by measuring the joint space distance in the sagittal and coronal directions. The result of the research was analyzed using the T-test. Statistically, the result of the test showed a significant difference $(\alpha=0,05)$ between patients with disc displacement with reduction symptoms and the patients without symptoms, in sagittal and coronal views. The conclusion led to the difference in condyle positions in patients with the disc displacement with reduction and patients without the symptoms which meant there was a condyle position displacement that caused the distance alteration in joint space in sagittal and coronal directions.

Key words: Condyle position, cone beam computed tomography, disc displacement with reduction

\section{INTRODUCTION}

Temporomandibular joint is one of the stomatognathic system areas that holds an important role in mandibular movement. Temporomandibular joint is formed by mandibular condyle which is located in the mandibular fossa of temporal bone. ${ }^{1,2}$

Functional disorders that occur in temporomandibular joint may go with the symptoms like, pain or the occurrence of noise around the joint, primarily when moving the mandible; difficulty in opening the mouth widely; and sometimes the occurrence of headache. Consequently, symptoms identification and diagnosis enforcement is absolutely needed for the success of the treatment. ${ }^{1}$

The most significant information in order to enforcethe correct diagnosis of temporomandibular joint disorders can be derived from the history of pain and examination. Radiographic examination is one of the supporting factors to determine 
whether the condition of the temporomandibular joint is normal. The use of temporomandibular joint radiographic diagnosis has not reached its maximum point yet. The problem is, there are not many dentists that comprehend the clinical diagnosis method of temporomandibular joint disorders, and there are many temporomandibular joint disorders symptoms that are similar to dental and oral problems, so that the diagnosis and the treatment are merely focused on the dental problem..$^{1,3}$

Recently, eventhough the temporomandibular joint disorders are interesting dental and oral problems, the usage of radiographic diagnosis as a facilitator to support the treatment has not been much indicated yet. Consequently, the use of it is limited only to suspected patients or patients with jaw joint disorders. ${ }^{3}$

Temporomandibular joint dysfunction is related to the function alteration of condyle-disc or commonly known as internal derangement (disc derangement) that comprises disc displacement with reduction (clicking as its characteristic) and disc displacement without reduction (noted by locked jaw). The displacement of articular disc (disc displacement) shows a disorder possessing an abnormal relation characteristic between the articular disc, the condyle of the mandible and articular eminentia..$^{1,4}$

An accurate radiographic interpretation is a significant point. This radiography is useful in helping the diagnosis enforcement and the treatment of temporomandibular joint disorders. Due to variation of joint conditions and some limitations in radiographic technique, the use of radiography for temporomandibular joint often causes misinterpretation or over interpretation. ${ }^{1}$

There are some radiographic techniques that can be used to evaluate the condition of temporomandibular joint, such as, panoramic radiography, transcranial, transpharyngeal (infracranial), transmaxillars anteroposterior, and tomography. But those techniques have some drawbacks, they can only be seen in two dimensional directions with image distortion and also the radiation is rather high. In line with the advance of science and technology, the three dimensional radiographic technology in dentistry has been developed. One of them is the Cone Beam Computed Tomography (CBCT-3D) which is capable of imaging the hard tissue in the maxillofacial area. The radiogram in three dimensional format is imaged more complex with minimum distortion, shorter scanning period and with lower dose than the conventional Computed Tomography (CT). ${ }^{1,5}$

The accuracy of mandibular condyle position in the glenoidalis fossa has been a controversial topic. The observation related to the condyle position and its therapy implication has been a polemic since long time ago. ${ }^{2,6}$

Aragon et al. $^{6}$ used Linear Tomography and MRI to study the condyle position on 52 asymptomatic (without symptom) which showed normal population, and his findings were, $43 \%$ condyle is in the concentric position, $24 \%$ more to the posterior, and $38 \%$ more to the anterior. On the other hand, Pullinger et al. ${ }^{7}$ indicated that the highest percentage of condyle position located more to the posterior was found in the symptomatic patients is $52.5 \%$, $40 \%$ condyle in concentric position, and $75 \%$ in the anterior. Bean and Thomas $^{8}$ found small or no difference of joint space width between asymptomatic and symptomatic patients.

Based on those results, the writers were interested in conducting a research on some subjects facilitated by Cone Beam Computed Tomography radiography in order to find out whether there was a difference of condyle position between patients with and without disc displacement with reduction symptoms. Patients with disc displacement with reduction were chosen because this case was the symptoms of temporomandibular joint disorders that commonly happened and was often found at the clinic.

\section{METHODS}

This research was a descriptive and analytic survey research. The research sample populations were patients with TMJ joint disorders (disc displacement with reduction) that visited the Oral and Dental Hospital, Faculty of Dentistry Universitas Padjadjaran (RSGM FKG UNPAD) in February 2008 and some patients without symptoms for a checkup visit. Patients were male and female that met the criteria as the research subjects. The method used in sample taking was purposive sampling (chosen sample taking). The samples consisted of male and female patients 
that met the sample criteria: age above 18, had the disc displacement with reduction symptoms (clicking, deviation/deflection; pain and difficulty when opening mouth); never had any treatment because of temporomandibular joint disorders (surgery/non surgery); and never got any trauma.

The examination of mandibular condyle position to the fossa in sagittal direction was the joint space distance which was measured in antero-posterior directions. It was determined by:

$$
\text { Sagittal Index }: \frac{\text { posterior distance-anterior }}{\text { posterior distance+anterior }} \times 100
$$

The mandibular condyle position to the fossa in coronal directions was the distance of joint space was measured in medio-lateral direction. It was determined by:

$$
\text { Coronal Index }: \frac{\text { medial distance-lateral }}{\text { medial distance+lateral }} \times 100
$$

The radiographic equipment was Picasso Trio CBCT-3D radiography equipment (brand EpxImpla, type B applied part Impla, serial number 0165906, made in Korea), and a computer set.

Based on the examination result of the patients visited the Screening Department Oral and Dental Hospital, Faculty of Dentistry Universitas Padjadjaran, it was found that some patients had joint disorders with and without disc displacement symptoms which were indicated to have CBCT-3D radiography. The patients were asked if they were willing to become the objects of the research. To those who were willing, they were ordered to fill in the informed consents. Then they were asked to sit on the dental chair for an anamnesis, and continued to the clinical examination (extra oral examination). Then the examination forms were provided, they comprised name, sex, age, occupation, and address; Bad habits: bruxism, clenching, chewing on one side, holding chin on one side, sleeping on one side, etc; ever/never had trauma, surgery, tumor, headache and/or vertigo; and ear disorders/tinnitus.

After conducting anamnesis, the patients went through clinical examinations (extra oral and intra oral). The extra oral check included probability of face asymmetry; noting the relationship between maxilla and mandibular on the center line in order to see if there was any deviation or deflection; noting the mandibular movement scope in vertical and mediolateral directions; examination on temporomandibular joints by palpation to find out the movement and to check if there is joint noise or joint pain. The intra oral check includes: dental check (to see if there were carries, pulpitis, gangrene restoration, third molar impacted, teeth malocclusion, or pulled out teeth), teeth occlusion check using articulation paper to find out if there was a premature contact or interference. Based on the diagnosis, it would be determined patients with disc displacement with reduction diagnosis and patients without the symptoms.

\section{Radiographic imaging on the patients using CBCT-3D}

Radiographic imaging on the right and left temporomandibular joints with position of the mouth closed. The steps were: (a) Preparing CBCT$3 \mathrm{D}$ radiography (Picasso Trio) and its operational set; (b) Preparing the patient; the patient was asked to put off all metal things attached to his body, such as earrings, glasses, and necklace; (c) Putting on the apron on the patient as the radiation protector; (d) The patient stood up with a headrest on; (e) The patient was exposed with close mouth. The patient closed the eyes when the sliding equipment revolved; (f) The sliding equipment would be around the head and would revolve for about 20 seconds then stopped; (g) Within 1-2 minutes, the result was displayed on the monitor; (h) Conducting an observation on the imaging result and cut the result in sagittal and coronal directions of each joint, right and left.

Measurement conducted were measuring the posterior, anterior, superior, medial, and lateral distance joint space in sagittal and coronal directions. After conducting the imaging, all data would be displayed on the monitor. Then the condyle sagittal view would be determined by looking for the cutting point of the top condyle. Next, was measuring the fixed position, as seen on Figure 3.

Measuring in the sagittal view of right condyle with the mouth position closed: (a) T-U line was a horizontal line that was in line with lowest point of eminentia (horizontal fossa 
distance). (b) Determine the vertical line, A-B that tied up to the highest point of condyle and in line with the T-U line vertically; (c) Project T-U line to the middle point of $A-B$ that will become $\mathrm{P}-\mathrm{Q}$ line; (d) Determine point $\mathrm{O}$, that was the highest point on the condyle's top; (e) Determine point $\mathrm{R}$ that was the cutting point of $\mathrm{P}-\mathrm{Q}$ line with the outer condyle edge next to the posterior; (f) Determine point $S$, that was the cutting point of $\mathrm{P}-\mathrm{Q}$ line with the outer condyle edge next to the anterior; (g) Measure the distance between A-O, the distance was the superior space; (h) Measure the distance between P-R, it was the distance of posterior space; (i) Measure the distance between $\mathrm{S}-\mathrm{Q}$, that was the distance of anterior space; (j) Save the data by typing Save: cds msr.......(patient's name).

Measuring the coronal view was the same as the sagittal view, it should be determined the cutting position of the highest condyle in coronal direction first. Then the measuring of that position was taken, as seen in Fig. 4: (a) Determine the horizontal line, this line was in line with the horizontal line in the sagittal view; (b) Determine

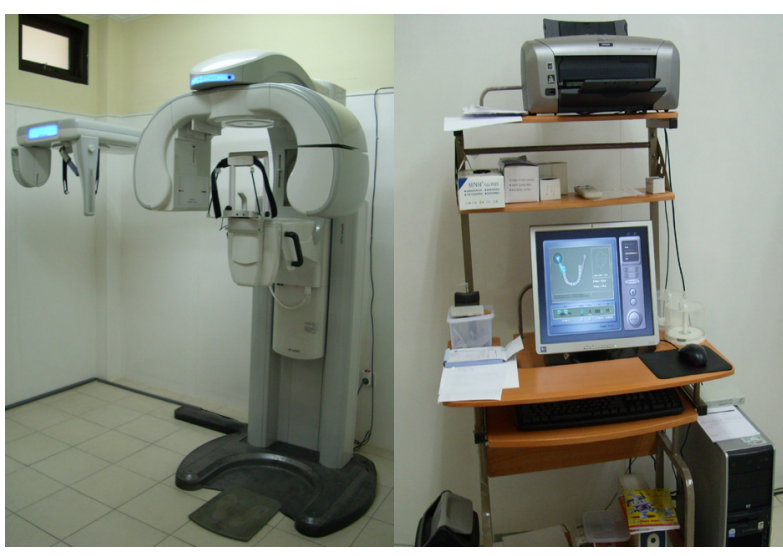

Figure 1. Picasso trio CBCT-3D and operational computer set unit.

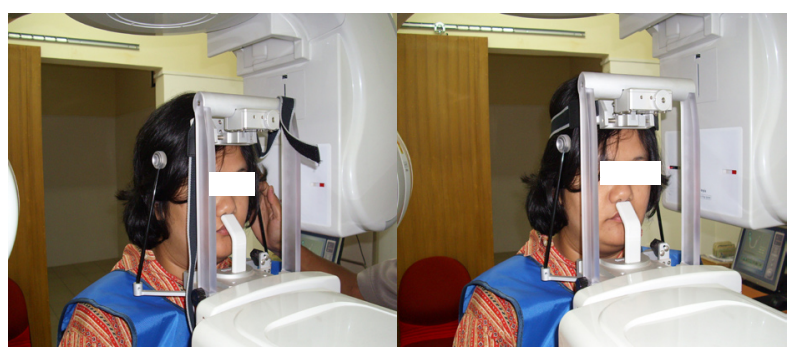

Figure 2. The position during radiographic imaging; (A) The patient stood up with a headrest on; (B) The patient was photographed with the mouth closed.
$\mathrm{K}-\mathrm{L}$ line, the horizontal line that was dragged from lateral to the articular medial fossa area; (c) Determine point $M$, that was the cutting line $\mathrm{K}-\mathrm{L}$ with the outer condyle edge next to the medial; (d) Determine point $\mathrm{N}$, that was the cutting line $\mathrm{K}$ $L$ with the outer condyle edge next to the lateral; (e) Determine $A^{\prime}-B^{\prime}$ line that were in line vertically from the horizontal line passing the highest point from condyle to fossa; (f) Determine point $O^{\prime}$ that was the cutting top of the condyle to $A^{\prime}-B^{\prime}$ line; (g) Measure the distance between K-M, that was the distance of medial space; (h) Measure the distance between $\mathrm{N}-\mathrm{L}$, that was the distance of lateral space; (i) Measure the distance between $\mathrm{A}^{\prime}-\mathrm{O}^{\prime}$, that was the distance of superior space; (j) Save the data by typing Save: cdc msr.....(patient's name). The same kind of measurement was conducted to the left condyle as well as the right one.

The accuracy of the measurement result of the temporomandibular joint space can be influenced by some factors, such as the ability and the accuracy of the operator, the radiographic imaging result, and the fatigue of the operator. For resulting accuracy and to minimize mistakes,

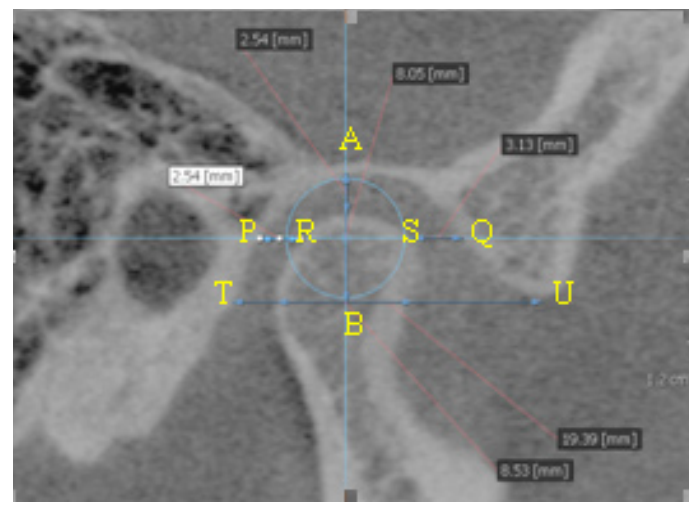

Figure 3. Measuring in sagittal view.

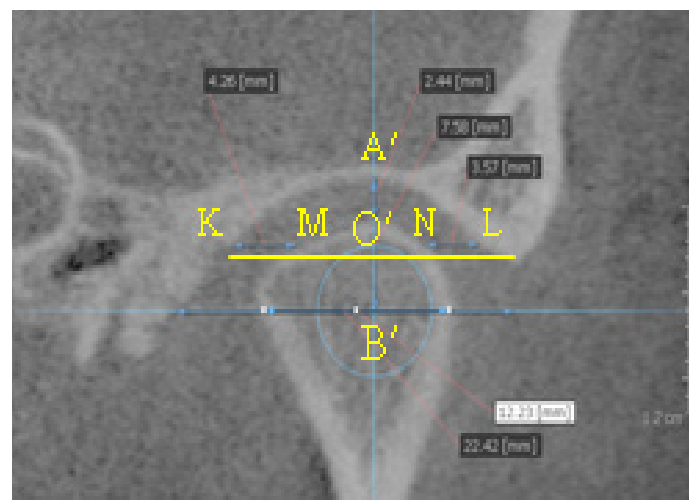

Figure 4. Measuring in the coronal view. 
this research conducted twice measurements. To overcome the fatigue of the operator, there were only measurement activities for 2 patients each day. Patients' screening was conducted in Screening Department of Oral and Dental Hospital and Specialist Clinic of Prosthodontic Faculty of Dentistry Universitas Padjadjaran. Radiographic imaging and CBCT 3-D radiography measurement were conducted in the Radiology Department of Oral and Dental Hospital, Faculty of Dentistry Universitas Padjadjaran. The research period started in February to May 2008.

\section{RESULTS}

This research was aimed to find out whether there were differences in the condyle position in sagittal and coronal directions on 11 patients with disc displacement with reduction (8 females and 3 males) and for the comparison, the radiographic imaging using the CBCT-3D to 3 patients ( 2 females and 1 male) that indicated no symptoms of disc displacement with reduction. The radiographic imaging using CBCT-3D radiography was focused on the right and left temporomandibular joints with the closed mouth and the maximum opened mouth positions. But this research was limited to measuring the closed mouth position.

After getting the data, the statistics analysis was conducted, such as count average (std) and also the statistics t-test to saw the condyle position on the patients with disc displacement with reduction symptoms and the patients without symptoms, as seen in the Table 1 and 2 .

\section{DISCUSSION}

This research was conducted using the radiography equipment $C B C T-3 D$ to measure the distance of joint space with condyle position during the mouth closed. Through the radiographic imaging using CBCT-3D, it could be measured the distance of joint space in sagittal, coronal, and axial directions.

In Table 1, it is seen that there was a significant difference of average point (statistically) of joint space distance in sagittal direction on the patients with disc displacement with reduction symptoms. Based on Table 1 , the hypothesis that states a difference of condyle position in sagittal direction on the patients with and without symptoms is accepted. So statistically, the distance of joint space in the anterior in sagittal direction in patients with disc displacement with reduction symptoms with the samples without the symptoms is not equal. This means, there has been a displacement of condyle position that leads to the alteration of joint space distance in sagittal direction.

The measurement results through CBCT3D show the difference of joint space in sagittal, coronal, and axial directions among patients with disc displacement with reduction symptoms and patients without the symptoms. This is in line with the research conducted by Katzberg et al. ${ }^{18}$ that indicated the significant difference on the condyle position between joints of patients with the symptoms and patients without symptoms.

But there are some researchers that put forward some deviant opinions. Bean and Thomas ${ }^{8}$ used the transcranial radiography to analyze the condyle position. They stated that the joint space distance had no difference on the symptomatic or asymptomatic patients.

In this research, the measurement result shows that there was a difference not only in

Table 1. Measurement analysis of joint space in sagittal direction on the patients with and without DDwR symptoms.

\begin{tabular}{ccccccc}
\hline Joint position & Symptoms & Average & Std & N & T test & Sig (2-tailed) \\
\hline \multirow{2}{*}{ Sagittal } & + DDR & 0.097 & 0.185 & 22 & \multirow{2}{*}{2.230} & $0.049^{*}$ \\
& -DDR & 0.248 & 0.138 & 6 & & \\
\hline
\end{tabular}

Table 2. Measurement analysis of joint space in coronal direction on the patients with and without DDwR symptoms.

\begin{tabular}{ccccccc}
\hline Joint position & Symptoms & Average & Std & N & T test & Sig (2-tailed) \\
\hline \multirow{2}{*}{ Coronal } & + DDR & 0.231 & 0.400 & 22 & \multirow{2}{*}{2.806} & $0.011^{*}$ \\
& - DDR & -0.236 & 0.254 & 6 & & \\
\hline
\end{tabular}

Note:* There is a significant difference; $a=0.05$. 


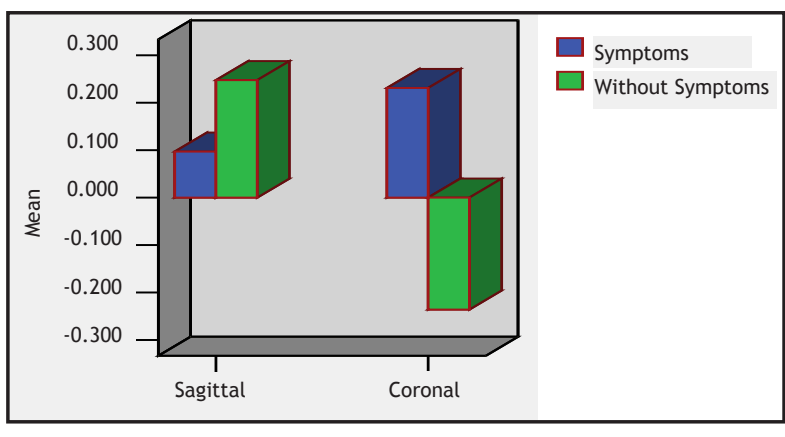

Figure 3. The average of ratio measurement of joint space distance in sagittal and coronal directions on the patients with symptoms and the patients without symptoms.

sagittal direction but also in coronal view. The average of the joint space in the lateral was narrower than the space in the medial so that it can be concluded that the tendency of the average samples has altered to the lateral direction. The alteration in the medial-lateral directions can be exposed using the CBCT-3D radiography, while the transcranial radiography that is commonly used is not capable of imaging the medial-lateral directions, but merely in lateral view (anteriorposterior directions).

Patients with disc displacement with reduction symptoms show the disc displacement to the anterior or to the anteromedial position. This happens due to the connection alteration between the articulars and condyle discs. The discs are tied up to the condyle with the disc ligament on the medial and lateral areas, and if the disc slips or displaces, it can cause the alteration of condyle position that leads to dysfunction. ${ }^{1,11}$

According to Iceberg ${ }^{11}$, the condyle position with displaced disc was found to be displaced to the posterior, central, and anterior. The highest percentage is the displacement to the posterior in sagittal direction. On patients number 5,8 , and 11 , the right joint in sagittal view, the condyle position moves to the posterior that makes the space in the anterior wider and the joint space in the posterior gets narrower. While the left side of condyle position seems to move to the anterior, the joint space in the anterior gets narrower, but it is wider in the posterior. On patient number 3 , the condyle position moves to posterior bilaterally, different from patient number 10 , the condyle position is more in the anterior, bilaterally. ${ }^{13}$

On patient number 1 (sample without symptoms), it is seen that the joint position moves to the anterior noted by the joint space distance. This is in line with the literature that states in some normal joints, condyle is found in central position, less than a half of the joints and they can be in anterior position or extremely posterior. Disc displacement also exists in the asymptomatic joints. Consequently, it is normal to find some variations in normal condyle position. But it can also be found some variations of condyle position in the joints with normal disc position (no displacement). ${ }^{13,14}$

On the sample patients without symptoms, number 1 , even though the condyle position had displaced, it didn't show any TMJ disorder symptoms. This might happen due to the fact that every individual has a unique ability to adapt to any condition change. ${ }^{1}$

This research used CBCT-3D radiography $3 \mathrm{D}$ tomography as the basis, with the exposed image is not only viewed in lateral aspect, such as transcranial radiograph, but we can also see and analyze the joint position in coronal view. However, condyle displacement in transverse direction (transverse displacement) can cause inconvenience of joints and other complications, even if the displacement is less than $1 \mathrm{~mm} .{ }^{14}$

As seen on patient number 4 , in the coronal view, it can be seen that the right joint displaces more to the medial so that the medial joint space becomes narrower than the lateral. On the contrary, on the left side, the medial joint space is wider than its lateral. This means, the joint has displaced in transverse direction (transverse displacement). Transverse displacement of condyle can be triggered by incorrect occlusion. When this occurs for a long period, it can create spasm of the pterigoid lateral muscle. From the clinical examination on patient number 4 , pain was found on the pterigoid muscle, both lateral and medial so this might trigger irreversible structural change on the joints and their surrounding structures. ${ }^{14}$

Another joint displacement is distraction, where the superior joint space gets wider and the condyle head moves down. It is estimated, if the superior joint space gets wider, the thickness of the disc is abnormal. In this research, 3 patients (number 4,7, and 10) had their superior space widen. The result of joint space distance measurement on those three patients is bigger than other patients. The average is $4-6 \mathrm{~mm}$. In 
fact, the normal joint space distance of superior joint is $2.15 \pm 0.54 \mathrm{~mm} .{ }^{10,14}$

According to the observations, patients with disc displacement symptoms undergo a deviation. The deviation is noticed by observing the position of the center line of mandibular to the center line of the upper face during opening and closing the mouth. If both lines are in the same vertical area, it means the track is normal. Some kinds of deviations are commonly found to one direction (to the right or left) or to both directions (to the left and right so that the track is zigzag). From all the samples with symptoms, there are 8 patients undergo the deviation to the right, and the rest (3 patients) had it to the left. This might happen based on the result that there was a significant difference in the coronal direction which means there was a joint displacement in the lateral direction. So it can be concluded that if there was a deviation to the left, then there would be joint distance change in the right side. ${ }^{15}$

Based on the ratio count result of joint space distance in sagittal direction, the percentage of condyle displacement in patients with disc displacement with reduction was, the most displacement is to the posterior, $50 \%$, concentric tendency $45 \%$, and to the anterior was only $5 \%$. This was in line with the research conducted by Kurita et al. ${ }^{13}$ that showed a tendency of condyle position displacement to the posterior on patients with internal derangement with reduction. Research of Peter et al. ${ }^{16}$ also showed an appropriate result. They found that patients with disc displacement with reduction had their condyle position more to the posterior compared to the other diagnosis (disc displacement with reduction and without symptoms). This was also in line with Pullinger et al. ${ }^{7}$ when they made a research on the asymptomatic patients that showed the most condyle position was more to the posterior, $52.5 \%$ in posterior, $40 \%$ condyle was in concentric condition, and $7.5 \%$ was in the anterior. On the contrary to Berghe et al. ${ }^{17}$ and Katzberg et al. ${ }^{18}$ who studied the condyle position on radiography and its connection to internal derangement, they were not able to prove that the position which was more to the posterior was connected to the internal derangement.

Based on the information from the radiographic imaging, such as the narrower or wider joint space, it will give a great role in determining joint disorder therapy, like the splint occlusal, so that the splint thickness can be fitted to the joint space condition between the right and left joint which may have different thickness. In addition, it can also determine the kind of splint that is going to be used, whether it needs any reposition or not. Since the variations of condyle position in the joint without symptoms have been found, the treatment plan which mostly leads to get the condyle to the middle of fossa position should be concerned.

What makes the result of the research varied is because of the technical factor or other variable that cannot be controlled during the research. For instance, the operator still might be lack of ability due to the equipment usage in the research is a new technology and the last factor is the limited number of samples. This research shows that the $C B C T-3 D$ radiography can be used as a facilitator in checking joint space distance, not merely in lateral aspect but also in coronal or even axial directions, so that it is regarded to be valid and accurate to be applied in a clinic.

\section{CONCLUSION}

Based on the result of the research using the $C B C T-3 D$ radiography, it can be concluded that there is a difference of condyle position on patients with disc displacement with reduction symptoms and on the patients without the symptoms in the sagittal and coronal views. The condyle position on patients with disc displacement with reduction is found more to the posterior in the sagittal view. CBCT-3D can be used to expose the existence of condyle displacement both in sagittal view (anteroposterior direction), coronal (transversal), or even axial (super-inferior) so that it can be used as a facilitator to determine a disorder diagnosis.

\section{SUGGESTION}

Since the use of CBCT-3D technology in the cases of temporomandibular joint disorders is quite accurate, consequently it is suggested to optimize more the use of the equipment especially for exposing the position, anatomical structure (shape), and joint space distance. Socializing the use of the Cone Beam Computed Tomography 
to help enforcing the temporomandibular joint disorder diagnosis. The importance of the use of CBCT-3D to optimize all diagnosis implications on temporomandibular joint disorders and other disorders around head and neck must be studied more. To get a more accurate result, it is suggested to have more research with bigger number of samples.

\section{REFERENCES}

1. Okeson JP. Management of temporomandibular disorder and occlusion. $6^{\text {th }}$ ed. St. Louis: MosbyYear Book, Inc.; 2007. p. 178-95,258-65.

2. Kaplan AS, Assael LA. Temporomandibular disorders, diagnosis and treatment. New York: W.B. Saunders Co.; 1991. p. 324-7.

3. Muljono G. Penentuan posisi radiografik kondilus sendi rahang dengan metode pengukuran kuantitatif menurut Pullinger untuk menunjang perawatan gigi. Jakarta: Kumpulan Makalah KPPIKG X 1994:435-45.

4. Sam B. Aplikasi Cone Beam 3D CT-Scan dalam pemeriksaan radiografi untuk diagnosa kelainan TMJ. Bandung: Kumpulan Makalah PIIKG IPROSI I 2007:10-7.

5. Aragon HB, Tallen RH, Katzberg RW, Kyrkanides S, Moss ME. Condyle position as a predictor of temporomandibular joint internal derangement. J Prosthet Dent 1999;82:205-8.

6. Pullinger AG, Solberg WK, Hollender L, Guichet D. Tomographic analysis of mandibular condyle position in diagnostic subgroups of temporomandibular disorders. J Prosthet Dent 1986;55:723-9.

7. Bean LR, Thomas CA. Significance of condylar position in patients with temporomandibular disorders. JADA 1987;114:76-8.

8. Hassanin MS, El-Zanaty A, Khan $N$, Rosenberg $\mathrm{H}$. Corrected lateral tomographic analysis of growth and development of the temporomandibular joint. Saudi Arabia Dent J 1995;3:(7):144-7. [cited 2007 Aug 20]. Avalaible from:www.sdsjournal.com.
9. New York Presbyterian Hospital. Internal derangement disorders (Temporomandibular joint). [cited 2008 March 14]. Available from: http://www.med.cornell.edu/.

10. Quinn PD. Color atlas of temporomandibular joint surgery. St. Louis: Mosby Inc.; 1998. p. $7,16,18,22,23$.

11. IsbergA. Temporomandibular joint dysfunction, a practitioner's guide. Sweden: Isis Medical Media; 2000. p. 39-41,90.

12. Gerber A, Steinhardt G. Dental occlusion and the temporomandibular joint. Chicago: Quintessence Publishing Co., Inc.; 1990. p. 28-39.

13. Mardjono D. Hubungan antara pola mengunyah kebiasaan yang salah dengan disfungsi sendi temporomandibula pada orang dewasa di Jakarta. Dissertation. Bandung: Universitas Padjadjaran; 1989. p. 4-5,32-3.

14. Peter R, Lorenz J, Marc PJ. Magnetic resonance imaging-based joint space measurements in temporomandibular joints with disc displacements and in controls. J Oral and Maxillofac Radiol 2000;90(2):240-8 (Abstract). [cited 2008 Aug 18]. Available from:http:// pt.wkhealth.com.

15. Berghe V, Deboever J, Andrians P. The interpretation of condyle position on radiographs: interexaminer reliability and relationship with clinical parameters. J Oral Rehabil 1988;15:211. (Abstract).

16. Katzberg RW, Keith DA, Ten Eick WR, Guralnick WC. Internal derangements of the temporomandibular joint: An assessment of condyle position in centric occlusion. J Prosthet Dent 1983;49:250-4.

17. Kurita $H$, Ohtsuka A, Kobayashi $H$, Kurashina K. A study of the relationship between the position of the condylar head and displacement of the temporomandibular joint disc. Dentomaxillofac Radiol 2001;30:162-5. [cited 2008 Aug 19]. Available from: http:// dmfr.birjournals.org/. 